\title{
Spitzenmathematik in der Präzisionsmedizin
}

Die Überprüfung der Gen-Expression der Rezeptoren auf einem Gen-Chip und die Zusammenführung aller Daten in einem mathematischen Modell erhöht die Treffsicherheit im Ergebnis: Mit diesem Konzept lässt sich die diagnostische Sicherheit bei der Auswahl der Brustkrebstherapie deutlich erhöhen, wie Wissenschaftler der MedUni Wien in einer interdisziplinären Kooperation zeigen konnten.

Die Wahl der passenden, individuellen Therapie bei Brustkrebs hängt von der Bestimmung der Rezeptoren für Östrogen, Progesteron und HER2 ab. Das wird derzeit mittels Immunhistochemie (IHC) als Gold-Standard durchgeführt. In fünf bis zehn Prozent aller Fälle kann diese Untersuchung von Tumorgewebe aber zu falsch negativen oder falsch positiven Ergebnissen führen - mit schwerwiegenden Folgen für die Betroffenen. Die Antihormontherapie bei Rezeptorpositivem Brustkrebs blockiert den Antrieb der Krebszellenentwicklung, eine vergleichsweise belastende Chemotherapie ist nicht nötig, könnte aber ohne lebensbedrohliche Folgen angewendet werden. Hat die IHC keinen positiven Rezeptorstatus ergeben, wird üblicherweise eine Chemotherapie durchgeführt. Ergibt die IHC jedoch ein „falsch positives" Ergebnis, kann die Hormontherapie lebensbedrohlich sein.

Um die Sicherheit bei der Feststellung des Rezeptor-Status zu erhöhen, haben die Bioinformatiker an der MedUni Wien auf der Grundlage der Daten von 3241 Patienten aus 36 klinischen Studien für jeden Rezeptor ein Gen-Modell entwickelt. „Vor der Bildung des Eiweißstoffes für den Rezeptor liefert das Gen zunächst eine RNA-Kopie, die den ,Bauplan' für den Rezeptor darstellt", erklärt Univ.-Prof. Dr. Wolfgang Schreiner vom Institut für Biosimulation und Bioinformatik den Mechanismus: „Mit Hilfe des GenChips können wir nachweisen, ob diese RNA-Kopie im Tumorgewebe vorhanden ist." Gleichzeitig wurden jeweils auch so genannte Co-Gene identifiziert, die im Gen-Netzwerk am zweitstärksten mit der Rezeptorbildung zusammenhängen.

\section{Sicherheit gegen $\mathbf{1 0 0} \%$}

Die Informationen aus der IHC und aus der Expression der RezeptorGene sowie der Co-Gene wurden in ein solides, mathematisches Modell gegossen, mit dessen Hilfe man ziemlich genau falsche Befunde ausschließen kann. „Diese Reihe könnte man beliebig lange fortsetzen", so Schreiner. "Wir könnten nun weitere Omics-Datenquellen mit in unsere Analyse nehmen, eine nach der anderen. Bis wir bei den falsch positiven oder negativen Befunde fast gegen Null gehen. Das heißt dann Sicherheit." (www.ncbi.nlm.nih.gov/ pubmed/30117066)

Diese Fusion von Omics-Daten, also molekularbiologischen Daten aus verschiedensten Blickrichtungen, wird es den Wissenschaftlern künftig ermöglichen, bei der Diagnose und Therapie immer präziser zu werden. „Wir sehen unsere Aufgabe darin, die Spitzenmathematik für die Precision Medicine nutzbar zu machen", so Schreiner.

\section{Einsatz in der klinischen Praxis}

„Die Herausforderung ist, eine maßgeschneiderte Therapie anzubieten und damit gezielter und genauer die richtige Behandlung durchführen zu können, um nicht unnötig nebenwirkungstragende Behandlungen anzuwenden. Das Ziel des Comprehensive Cancer Centers der MedUni Wien und des AKH Wien (CCC) ist eine noch selektivere und individuellere Behandlung", stellt Univ.-Prof. Dr. Heinz Kölbl, Leiter der Klinischen Abteilung für All-

gemeine Gynäkologie und gynäkologische Onkologie, die ebenfalls an der Studie beteiligt war, fest.

Die Hinzunahme von molekularbiologischen Daten zur klassischen Immunhistochemie sei ein Schritt hin zu einer noch exakteren Tumorcharakterisierung, ergänzt Univ.-Prof. Dr. Christian Singer, Mitglied des CCC und Leiter des Labors für erblichen Brustund Eierstockkrebs und Leiter der Senologie an der Univ.-Klinik für Frauenheilkunde der MedUni Wien: „Weil der Rezeptorstatus weiterhin einen der wichtigsten tumorbiologischen Parameter darstellt."

Wien klin Mag 2018 · 21:249

https://doi.org/10.1007/s00740-

018-0264-8

(c) Springer-Verlag GmbH Austria, ein Teil von Springer Nature 2018

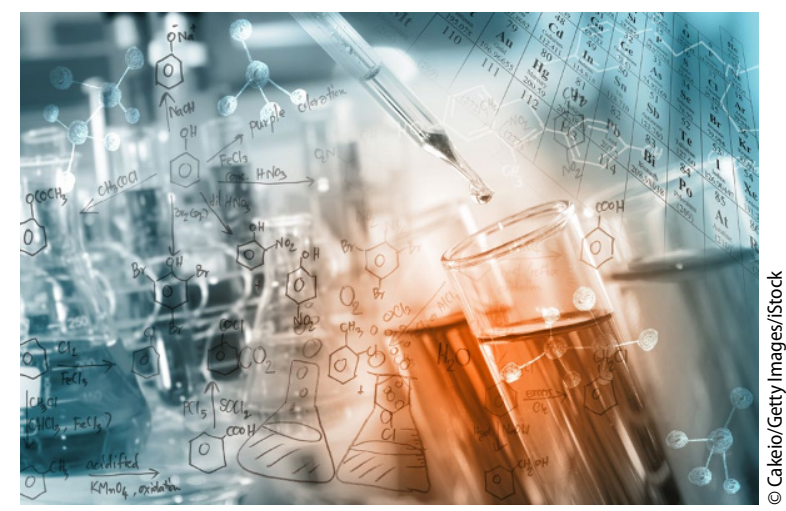

